\title{
Tendon transfers in radial nerve palsy with fractures of the humerus: Case reports
}

G. K. Museve, MBChB, MMed (Surg), FCS (ECSA), Fellowship (UK), Department of Orthopaedic Surgery, College of Health Sciences, University of Nairobi, P. O. Box 29829 - 00202 Nairobi, Kenya. Email: gkmuseve@yahoo.co.ke

\section{SUMMARY}

Case 1: A 25 year old right handed male soldier who was referred to Kenyatta National Hospital (KNH) in February 2008, from Burundi, with non-union of the left humerus and wrist drop. He sustained a compound fracture of the humerus and wrist drop following a gunshot injury a year earlier. Open reduction, plating of the humeral fracture and bone grafting coupled with tendon transfers resulted in significant initial functional recovery of the limb at $4 \frac{1}{2}$, months post-operatively.

Case 2: A 29 year old right handed paramilitary male sustained fractures of the right humerus and right radius and ulna in a lorry accident. A wrist drop and inability to actively extend the fingers and thumb was noted when he was admitted to KNH in March 2008. Internal fixation of fractures was done. The radial nerve was in continuity. There was no radial nerve recovery after 19 months. Tendon transfers were done resulting in significant initial functional recovery noted at $31 / 2$ months post operatively. Tendon transfers to restore function is a good option where radial nerve recovery is not anticipated. This can also save careers.

\section{INTRODUCTION}

Loss of hand function secondary to radial nerve injury can dramatically impair the person's ability to perform normal activities of daily living. When nerve repair is not possible or the window of opportunity to repair is missed, tendon transfers can be done to restore lost functions. In cases where there is associated non-union of the humerus fracture, functional loss is exercebated. Tendon transfers have been used in upper limb reconstruction for more than a century and various surgeons have contributed greatly to the field, (1-5). The field has progressed immensely and is still developing.

\section{CASE REPORTS}

Case 1: A 25 year old right handed male soldier was referred to Kenyatta National Hospital (KNH) in February, 2008 , with non-union of the left humerus and wrist drop. He had been shot a year earlier sustaining a compound fracture of the left humerus. The fracture went into nonunion on conservative management.

On admission, the left upper limb was wasted and had scars on the arm. He had non tender non- union on the left humerus, supple wrist and finger joints, limited passive supination, wrist drop, no active extension of thumb and all metacarpophalangeal joints but normal triceps function. Nerve conduction tests showed absence of left radial nerve activity. Median and ulner nerve functions were normal. Radiographs revealed an atrophic non-union with a large defect of the humerus.

Open reduction, plating and bone grafting of the humerus was done. Proximal radial nerve stump was identified but not the distal stump. Two weeks later tendon transfers were done.:-

Flexor carpi radials to extensor digitorum communis, pronator teres to extensor carpi radialis brevis and palmaris longus to extensor policis longus.

A cast was applied with wrist extension $40^{\circ}$, metacarpophalangeal and finger extension for four weeks followed by dynamic splintage, occupational therapy including nerve stimulation. Additional bone grafting was done.

At the time of last review at about $4 \frac{1}{2}$ months post operatively he had attained good active extension of the fingers and thumb.Active thumb abduction was moderate. Active wrist extension was grade 2 and improving. The fracture was healing. He was still on follow up. 


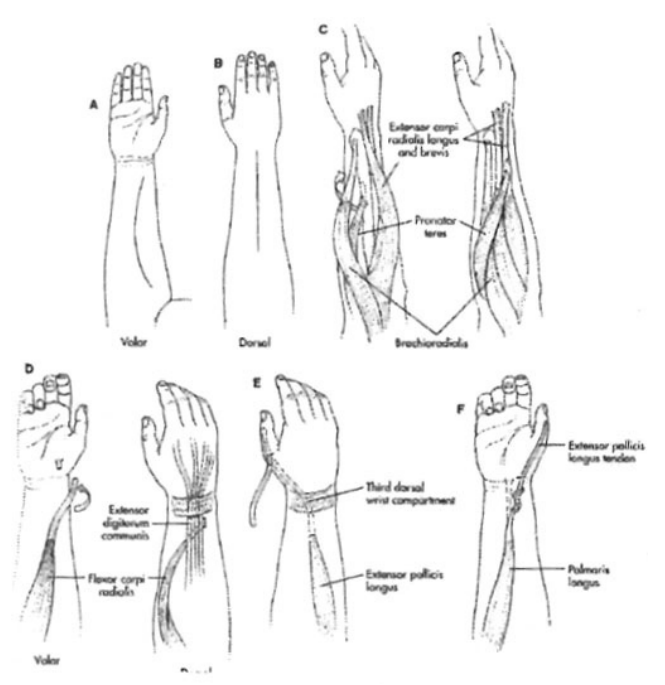

Figure 1: Tendon transfers

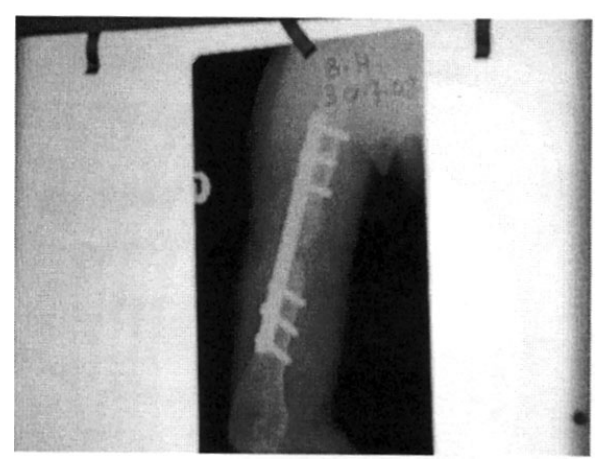

Figure 2: Case 1: Plated and grafted humeral fracture

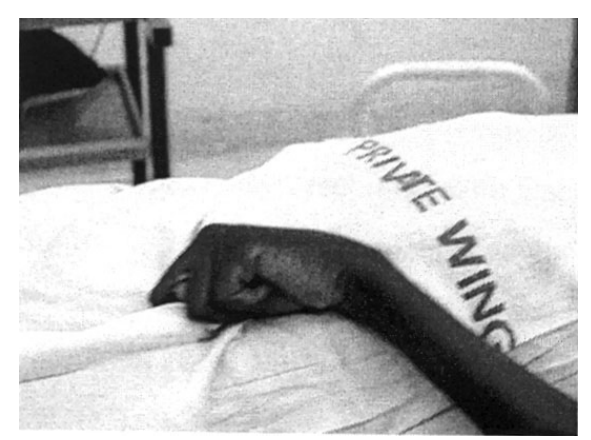

Figure 3: Case 1: Left wrist drop

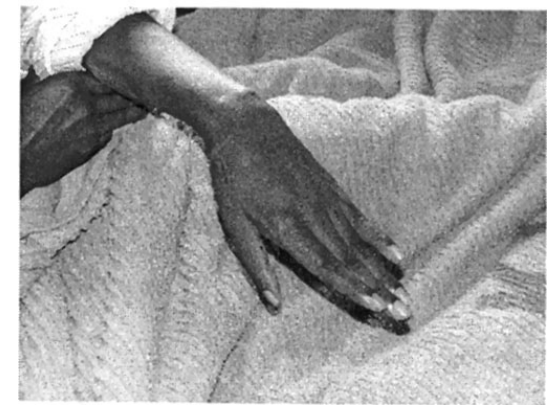

Figure 4: Case 1: Finger thumb extension and thumb abduction

Case 2: A 29 year old right handed paramilitary male who sustained fractures of the right humerus and right radius and ulna in a lorry accident. He was admitted to $\mathrm{KNH}$ in March 2007 where a right wrist drop and neurological signs similar to case one were noted. Plating of the fractures was done. The radial nerve was in continuity. No radial neurological recovery was evident after 19 months. He had some stiffness supination. Tendon transfers were done as in case one, except that the flexor carpi radialis was transferred to both extensor carpi radialis longus and brevis.

At $3 \frac{1}{2}$ months he had good active extension of the fingers and thumb and wrist extension had power grade III. Thumb abduction was good. He was still on follow up.

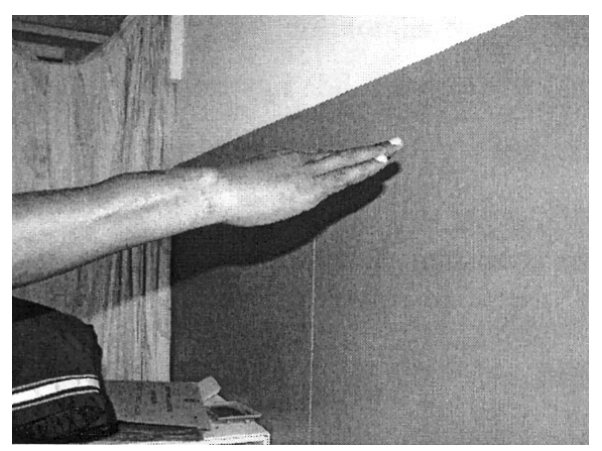

Figure 5: Case 2: Wrist and finger extention

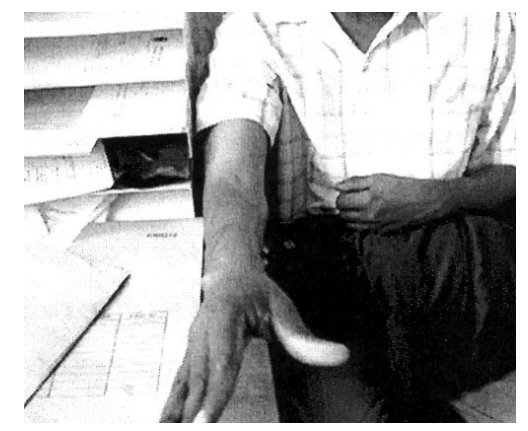

Figure 6: Case 2: Thumb abduction and extension 


\section{DISCUSSION}

Radial nerve palsy associated with fractures of the shaft of humerus is a common lesion $(6,7)$. Overall prevalence in a review of 21 papers was $11.8 \%$ with the middle and middle-distal parts of shaft having a significantly higher association of radial nerve palsy than other parts, with tranverse and spiral fractures contributing more than comminuted and oblique fractures. Overall rate of recovery was $88.1 \%$ with spontaneous recovery reaching $70.7 \%$ in patients treated conservatively (8), hence some authors $(9,10)$ oppose early exploration of the nerve in closed fractures. However several authors $(11,12)$ have advocated that all radial nerve injuries associated with humeral shaft fractures should be treated with early exploration citing the following advantages to support this position.

a). The status of the nerve can be ascertained at the time of injury thereby facilitating decisions regarding nerve repair or tendon transfers.

b). Stabilisation of the fracture by internal fixation protects the radial nerve from further damage.

c). Early exploration is technically easier and safer.

Khan and Birch in their study of iatropathic injuries of peripheral nerves 26 out of 48 (56\%) developed lesion following open reduction and fixation of humerus (13). Neurological recovery was not expected in both cases after a year or more following injury. At exploration, during the surgical management of the non-union of the humerus, the radial nerve had been transected and only the proximal stump was present. Due to gross functional loss of the hands, tendon transfers were done to restore function in both cases. At $41 / 2$ and $31 / 2$ months respectively both had significant functional recovery of active extension and abduction of the thumb and active extension of the fingers. The active wrist extension were grade 2 and 3 respectively and were still improving.

In radial nerve palsy, patients cannot extend the fingers and thumb and abduct the thumb making grasping objects difficult. The loss of wrist extension further impairs grasp and particularly power grip. (14). These functional losses need to be restored by tendon transfers.

The principles of tendon transfers include supple joints, adequate strength of chosen tendon, appreciation of the amplitude of motion, straight line of pull, one tendon one function, availability of expendable donor and tissue equilibrium (15). Intense postoperative physical therapy after a three week splintage is crucial for good outcome (16).

A wrist flexor transferred to the finger extensors does not have sufficient amplitude of excursion to simultaneously extend the wrist and fingers. The patient uses the tenodesis effect generated by active volar flexion of the wrist to enhance the effective excursion of the tendon and thereby achieve excellent active extension of the fingers. However simultaneous extension of the fingers and wrist is possible with superficialis transfer (15).

The two cases, while still on follow up, have demonstrated significant functional recovery following tendon transfers. Where no neurological radial nerve recovery is anticipated, tendon transfers is recommended to restore lost function and also save careers.

\section{REREFENCES}

1. Zancolli, E. A. Claw-hand caused by paralysis of the intrinsic muscles; a simple surgical procedure for its correction. J. Bone Joint. Surg. Am. Oct. 1957; 39 - A (5): 1076 - 1080.

2. Pulvertaft, R.G. Techniques in hand surgery. J. Bone Joint Surg. 1960: 42 A: 1907.

3. Burkhalter, W. E. Early tendon transfer in upper extremity peripheral nerve injury. Clin. Orthop. Relat. Res. 1974; 104: $68-79$.

4. Moberg, E. Reconstructive hand surgery in tetraplegia, stroke and cerebral palsy: some basic concepts in physiology and neurology. J. Hand Surg. (Amer). 1976; 1(1): 29 - 34.

5. Riordan, D.C. Tendon transfers in hand surgery. J. Hand Surg. (Am). 1983; 8(5 pt 2): 748 - 753.

6. Canale, S.T. Fracture of humeral shaft with radial nerve palsy. In : Canale ST ed Campbell's operative orthopaedics Vol. 3, Tenth ed St. Louis; Mosby Year Book. 2003: 3016.

7. Rockwood, C.A.Jr, Green, D.P., Bucholz, R.W. and Heckman, J.D. Rockwood and Green's fracture in adults. Fourth ed Philadelphia: Lippincott - Raven publishers. 1996: 1043 1045.

8. Shao, Y.C., Harwood, P., Grotz, M. R. W., Limb, D. and Giannoudis, P.V. Radial nerve palsy associated with fractures of the humerus. A systematic review. J. Bone Joint Surg. 2005; 87 - B: 1647 - 1652. 
9. Shah, J.J. and Bhatti, N.A. Radial nerve palsy associated with fractures of the humerous: a review of 62 cases. Clin. Orthop. 1983; 172: 171 - 176.

10. Pollock, F.H., Drake, D., Bovill, E.G., Day, L. and Trafton, P.G. Treatment of radial neuropathy associated with fractures of the humerus. J. Bone. Joint. Surg. (Am). 1981; 63 - A: 239 - 243.

11. Packer, J.W., Foster, R.R., Garcia, A. and Grantham, S.A. The humeral fracture with radial nerve palsy: Is exploration warranted? Clin. Orthop. 1972; 88: 34 - 38.

12. Sim, F.H., Kelly, P.J. and Henderson, E.D. Radial nerve palsy complicating fractures of the humeral shaft. J. Bone Joint Surg. 1971; 53 A: 1023 - 1024.
13. Khan, R. and Birch, R. latropathic injuries of peripheral nerves J. Bone. Joint. Surg. Nov 2001; 83 - B: 1145 - 1148.

14. Labosky, D.A. and Waggy, C.A. Apparent weakness of median and ulnar motors in radial nerve palsy. J. Hard. Surg. 1986; 11A: 528 - 533.

15. Green, D.P. Radial nerve palsy. In Green: D.P ed operative hand surgery, Vol 2 Third ed. Churchill Livingstone. 1993, 1401 - 1415.

16. Canale, S.T. Paralytic hand in Canale ST ed Campbell's operative orthopaedics, Vol. 4, tenth ed St. Louis: Mosby. 2003: 3647 - 3650. 